\title{
Finalizan las estancias en Andalucía para técnicos del patrimonio de países socios del proyecto Delta
}

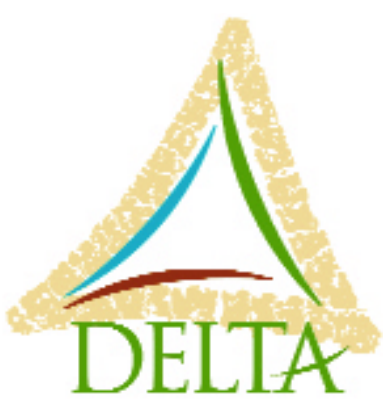

En el marco del proyecto DELTA -Desarrollo de sistemas culturales territoriales- (www.imednet.it/delta) se han desarrollado unas estancias formativas en Andalucía sobre planificación y gestión de sistemas culturales territoriales. Este proyecto está financiado por el programa Euromed Heritage II convocado por la Comisión Europea y en él participan 4 países europeos -Francia, Italia, Grecia y España- junto con 5 países del Mediterráneo -Argelia, Marruecos, Palestina, Israel y Malta.

El Instituto Andaluz del Patrimonio Histórico participa como socio en este proyecto y como tal fue el encargado de la organización de unas estancias formativas para técnicos de patrimonio de los países socios del Mediterráneo. Las estancias, que forman parte de un programa formativo completo que se inició en Malta con un curso teórico sobre la Planificación de los Sistemas Culturales Territoriales y ha continuado en nuestra región con las sesiones prácticas, concluyen de nuevo en Malta con una actividad de debate, reflexión y evaluación sobre los contenidos aprendidos y las experiencias visitadas.

Para la planificación de las estancias en Andalucía se diseñó un programa formativo a medida que permitiera a los participantes poner en práctica los conocimientos y conceptos teóricos adquiridos durante la primera parte del proceso formativo. Se trataba de conocer en profundidad experiencias y proyectos territoriales de nuestra región que giran en torno a los elementos patrimoniales y las componentes culturales. Se seleccionaron para ello experiencias y proyectos de gestión patrimonial en el territorio de diferente escala y tipologías como el turismo cultural y la conservación del patrimonio en contextos urbanos como Granada o Loja o de ámbito rural como Almedinilla; rutas culturales temáticas de ámbito regional como la Bética Romana o el Legado Andalusí; planes de desarrollo territorial integrados como el de la Serranía de Ronda o el Poniente Granadino; entidades culturales privadas como la Maestranza de Caballería de Ronda y del tercer sector como la cooperativa que gestiona el Centro de Interpretación del Sacromonte en Granada.

El programa ha combinado actividades y debates en sala con visitas y trabajo de campo. Los participantes han tenido la oportunidad de tener un contacto directo con agentes locales de diferente nivel institucional, grupos de desarrollo y asociaciones que representan tanto a organismos públicos como privados y entidades del tercer sector.

A lo largo de estas sesiones y como parte de los proyectos estudiados se nos han presentado tanto productos y reproducciones patrimoniales como actividades complementarias vinculadas al patrimonio y al desarrollo cultural. Así las Jornadas gastronómicas romanas de Almedinilla, el Festival
Etno-Sur de Alcalá la Real o el aceite elaborado por una almazara de la Ruta de la Bética Romana embotellado en un ungüentario.

Los 15 participantes procedían, como hemos señalado, de Marruecos, Argelia, Palestina, Israel y Malta y todos ellos eran profesionales de la conservación y gestión del patrimonio histórico vinculados a los proyectos piloto que se desarrollan como parte del proyecto DELTA. Por su formación académica destacaban los arquitectos, seguidos por los arqueólogos y otros profesionales de la gestión del patrimonio y la ordenación del territorio. El alto nivel de los participantes así como el interés que han manifestado a lo largo de las dos semanas de estancia han contribuido decisivamente al éxito de la actividad. Por otra parte la posibilidad de tener un contacto directo con proyectos reales así como con los técnicos y responsables de esos proyectos y experiencias visitadas han facilitado la asimilación y transmisión de conceptos claves como planificación, sensibilización, puesta en valor y difusión del patrimonio.

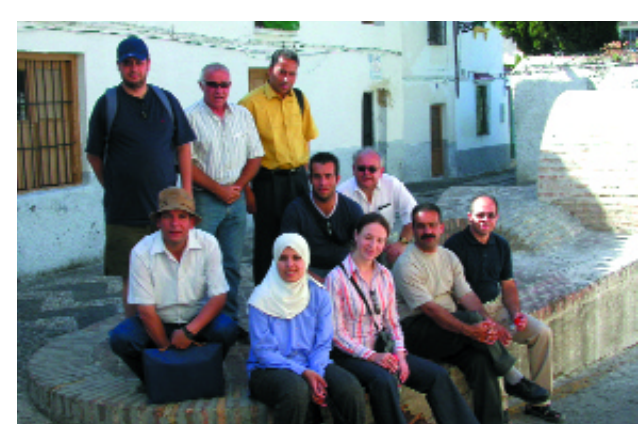

Participantes de las estancias en Andalucia durante su visita a Granada

Es necesario señalar la excelente acogida que nos han dispensado en todos los ayuntamientos, instituciones y proyectos visitados, tanto a nivel político como a nivel técnico, cumpliendo de este modo uno de los objetivos de las estancias, el contacto e intercambio directo entre los participantes y los agentes protagonistas del desarrollo territorial en Andalucia.

Como parte del necesario intercambio y reciprocidad de un proyecto de cooperación, durante las estancias, además de conocer proyectos de nuestra región, los técnicos participantes han tenido la oportunidad de presentar los proyectos piloto en que están trabajando en sus respectivos países y así hemos podido conocer de primera mano el diseño de itinerarios turísticos en la región de Ghardaia en Argelia, o la planificación y ordenación de los flujos de visitantes entre Fez, Meknes y Volubilis en Marruecos, o los programas de regeneración urbana que llevan a cabo en el área de Cottonera en Malta.

Pilar Tassara Andrade

Área de Cooperación IAPH-EPGPC 